\title{
Research on the relationship between China's carbon emission, economic growth and the development of new energy industry
}

\author{
Huimei Chen ${ }^{1}$, Yingchun Wang ${ }^{2}$, Haifeng Kang ${ }^{2}$ \\ ${ }^{1}$ School of management, Tianjin University of Technology, Tianjin 300384, China, 351342639@qq.com \\ ${ }^{2}$ School of management, Tianjin University of Technology, Tianjin 300384, China, 530129057@qq.com
}

\begin{abstract}
In view of the current domestic new economic form, under the trend of sustainable development, new energy industry has become a rising star. The development of new energy can improve the environment destroyed by the development of fossil energy to a certain extent. It is the primary task of environmental protection and energy development to study the specific relationship between China's current carbon emissions, economic growth and the development of new energy industry. Based on STR model, we can empirically study the impact of carbon emissions on the development of new energy industry, analyze the nonlinear relationship, and propose relevant strategies to promote the development of new energy industry and pay attention to the coordinated development of energy consumption and environmental protection.
\end{abstract}

\section{Introduction}

After the reform and opening up, China economic development level has made a great leap. In the face of the new economic situation, on the one hand, China is in the stage of supply side reform, and needs to break through the old mechanism and explore new endogenous power. On the other hand, China current environmental pressure is great, so promoting the development of new energy industry is in line with China environmental protection policies, and it is necessary to solve the environmental problems and energy supply at the same time. Therefore, it is of great significance to study the factors affecting the development of new energy industry. This paper mainly studies the impact of carbon emissions and economic growth on the development of new energy industry, so as to put forward relevant suggestions on the coordinated development of energy consumption and environmental protection while promoting the development of new energy industry. ${ }^{[1]}$.

\section{Data and model}

\section{1 model}

In recent years, STR model has been well applied in business cycle research, inflation, financial contagion and other fields, especially in the modeling and forecasting of macroeconomic phenomena. The general form of smooth transformation regression model is as follows. ${ }^{[2]}$

$$
Y_{t}=X_{t} \alpha+\left(X_{t} \beta\right) L\left(\theta, c ; s_{t}\right)+\delta_{t} \quad t=1, \cdots, T
$$

among $\alpha_{\text {and }}^{\beta}$ Is the parameter vector, $Y_{t}$ For the explained variable, ${ }^{X_{t}}$ For explanatory variables, ${ }^{\delta_{t}}$ It is a sequence of random perturbations which obey independent and identically distributed.

\subsection{Data sources and descriptive analysis}

In order to analyze the relationship between China new energy development and carbon dioxide emissions, it is necessary to construct variables to measure the degree of new energy development and carbon dioxide emissions. ${ }^{[3]}$. This paper selects China hydropower, wind power, solar energy and nuclear power generation from 2000 to 2019 as the indicators to measure the development degree of new energy industry, which is recorded as new (100 million kwh); secondly, using the carbon emissions of various provinces and cities calculated in this chapter to add up China carbon emissions from 2000 to 2019, which is recorded as $\mathrm{CO}_{2}$ (100 million tons).In order to ensure the stability of variable data ${ }^{[4]}$, the logarithm of carbon emissions and economic growth variables is taken as LNEW and $\mathrm{LCO}_{2}$, and the first-order difference is carried out respectively to obtain DLEW and $\mathrm{DLCO}_{2}$ series. The descriptive statistical results of each variable after the above treatment are shown in table 1 .

Table 1 descriptive statistical results

\begin{tabular}{|c|c|c|c|}
\hline variable & Max & $\min$ & variance \\
\hline LNEW & 9.6800 & 7.7740 & 0.6134 \\
\hline $\mathrm{LCO}_{2}$ & 8.0001 & 6.8562 & 0.3937 \\
\hline
\end{tabular}




\begin{tabular}{|c|c|c|c|}
\hline DLEW & 0.2183 & -0.0184 & 0.0595 \\
\hline $\mathrm{DLCO}_{2}$ & 0.1745 & -0.0088 & 0.0541 \\
\hline
\end{tabular}

\subsection{Stationary test}

Before constructing STR model, this paper will first use $\mathrm{ADF}$ test to verify the stationary of LNEW and $\mathrm{LCO}_{2}$. ${ }^{[5]}$.It can be seen from the following table that variables LNEW and $\mathrm{LCO}_{2}$ are not stationary, but after the firstorder differential treatment of variables $\mathrm{LNEW}$ and $\mathrm{LCO}_{2}$, DLEW and $\mathrm{DLCO}_{2}$ show certain stationary. STR model can be used for the next empirical analysis. The specific test results are shown in the ADF test statistics in Table 2.

Table 2 stationary test

\begin{tabular}{|c|c|c|}
\hline variable & T statistic & Is it stable \\
\hline LNEW & -0.0432 & no \\
\hline DLEW & $-7.0130 * * *$ & yes \\
\hline $\mathrm{LCO}_{2}$ & -1.2551 & no \\
\hline
\end{tabular}

\begin{tabular}{|c|c|c|}
\hline $\mathrm{DLCO}_{2}$ & $-3.2457 * * *$ & yes \\
\hline \multicolumn{2}{|c|}{ Note $" * * "$, " $* "$ and $" * "$ indicate that the parameters } \\
\hline
\end{tabular}
are significant at the significance levels of $1 \%, 5 \%$ and $10 \%$, respectively.

\subsection{Determination of lag order}

The stationary test shows that both LNEW and lco2 are first-order single integral sequences, which fail to pass the stationary test. ${ }^{[6]}$.In view of this, this paper will make an empirical analysis on DLEW and $\mathrm{DLCO}_{2}$ sequences obtained from their difference. The Granger causality test is carried out on DLEW and $\mathrm{DLCO}_{2}$ to determine the lag order of variables. From the test results, it can be concluded that only when the lag order is 2 and 3 , the original hypothesis that "DLEW is not the Granger cause of $\mathrm{DLCO}_{2}$ " can be rejected and the original hypothesis that "DLCO $\mathrm{C}_{2}$ is not the Granger cause of DLEW" can be accepted. This shows that under the assumption of linear model, carbon emissions can promote the development of new energy industry; however, the development of new energy does not improve carbon emissions, which is a oneway Granger causality.

Table 3 Granger causality test

\begin{tabular}{|c|c|c|c|c|}
\hline variable & Lag order & Null hypothesis & $\begin{array}{c}\mathrm{F} \\
\text { value }\end{array}$ & $\mathrm{P}$ value \\
\hline \multirow{2}{*}{$\begin{array}{c}\text { DLEW } \\
\text { DLCO2 }\end{array}$} & \multirow{2}{*}{2} & \multirow{2}{*}{$\begin{array}{c}\text { DLEW is not } \\
\text { The Gran of DLCO2 } \\
\text { The reason for that } \\
\text { DLCO2 is not } \\
\text { Glenn of DLEW } \\
\text { The reason for that }\end{array}$} & 8.9445 & 0.0000 \\
\hline & & & 0.3610 & 0.7180 \\
\hline \multirow{2}{*}{$\begin{array}{l}\text { DLEW } \\
\mathrm{DLCO}_{2}\end{array}$} & \multirow{2}{*}{3} & $\begin{array}{l}\text { DLEW is not } \\
\text { The Gran of DLCO2 } \\
\text { The reason for }\end{array}$ & 9.0340 & 0.0000 \\
\hline & & $\begin{array}{c}\text { DLCO2 is not the Gran } \\
\text { of DLEW } \\
\text { The reason for }\end{array}$ & 0.4023 & 0.6840 \\
\hline
\end{tabular}

\subsection{Model estimation and result analysis}

In this paper, firstly, according to the 1-3 order lag term and $0-2$ order lag term of DLEW and $\mathrm{DLCO}_{2}$, the least square method is used to make regression analysis on these nine combinations, and the results of log likelihood ratio statistics are obtained ${ }^{[6]}$.. By comparing AIC statistics and $\mathrm{C}$ statistics, the optimal combination of lag order of the model is determined. Secondly, the linear test is carried out on the variable. After rejecting the linear test, it needs to continue to be determined by sequential test $L\left(\theta, c ; s_{t}\right)$ Type. In the third step, t-o-o method is used to estimate the initial value of the model.

Table 4 model results

\begin{tabular}{|c|c|c|c|c|}
\hline \multicolumn{2}{|c|}{ variable } & Initial value & Estimated value & P value \\
\hline \multirow{4}{*}{ Linear part } & Constant term & 0.0698 & 0.0697 & 0.0660 \\
\cline { 2 - 5 } & DLEW(t-1) & -0.7167 & -0.7177 & 0.0144 \\
\cline { 2 - 5 } & $\mathrm{DLCO}_{2}(\mathrm{t})$ & 0.8728 & 0.8745 & 0.0465 \\
\hline
\end{tabular}




\begin{tabular}{|c|c|c|c|c|}
\hline & $\mathrm{DLCO}_{2}(\mathrm{t}-2)$ & 1.8166 & 1.8175 & 0.0275 \\
\hline \multirow{11}{*}{ Nonlinear part } & Constant term & -0.0116 & -0.0068 & 0.0845 \\
\hline & DLEW(t-1) & 0.5166 & 0.4964 & 0.0745 \\
\hline & $\mathrm{DLCO}_{2}(\mathrm{t})$ & -1.8000 & -1.7830 & 0.0435 \\
\hline & $\mathrm{DLCO}_{2}(\mathrm{t}-1)$ & 0.4981 & 0.4750 & 0.0602 \\
\hline & $\mathrm{DLCO}_{2}(\mathrm{t}-2)$ & -1.4360 & -1.4336 & 0.0398 \\
\hline & Gamma & 42.6583 & 81.7152 & 0.0948 \\
\hline & $\mathrm{C}$ & 7.7241 & 7.8472 & 0.0428 \\
\hline & AIC & & -5.9026 & \\
\hline & $\mathrm{R}$ & & 0.8755 & \\
\hline & Adjusted R & & 0.8830 & \\
\hline & SSR & & 0.0616 & \\
\hline
\end{tabular}

In the linear part of the model, DLEW (t-1) has a significant negative effect on China new energy growth. Through the empirical analysis of carbon emissions and new energy, this paper finds that there is a one-way Granger causality between carbon emissions and the growth of new energy industry. Specifically, the growth of carbon dioxide emissions has a one-way promoting effect on the growth of China new energy industry, which indicates that the growth of new energy industry does not have an effective impact on carbon emissions.

\section{Result analysis}

Based on the STR model, this paper starts from the overall perspective of the whole country, taking China 30 years from 2000 to 2019 as an example Based on the panel data of provinces and cities, this paper studies the relationship between the development of new energy industry and economic growth, carbon emissions and other six explanatory variables through empirical analysis. The results show that: there is a nonlinear relationship between the development of new energy industry and economic growth, carbon emissions and other explanatory variables with the growth of economic level, and the specific form is as follows: with the economic growth With the increase of economic growth level, the inhibition effect of economic growth on new energy development gradually turns into a driving role, and the economic growth level reaches 11.2650Economic growth, carbon emissions and other explanatory variables have a significant positive effect on the development of new energy. On the whole, economic growth has a negative effect on the development of new energy in the period of low economic level. However, the level of economic growth in most regions of China has a positive effect on the development of new energy, and the inhibitory effect of economic growth on new energy is mainly concentrated in the western region.

\section{Questions and suggestions}

\subsection{Give priority to the development of hydropower energy}

The government should adopt different development strategies according to different development stages of new energy industry. At the initial stage, governments at all levels should give priority to the development of hydropower energy and encourage the introduction of advanced new energy technologies. The government should take flexible measures to promote the development of new energy industry. First, the government should actively develop hydropower energy. The second is to actively introduce foreign advanced new energy technologies. Third, the central and local governments arrange special funds to support the development and utilization of new energy, and give full play to the different geographical advantages of various provinces and cities.

\subsection{Strategic transformation in eastern China}

The eastern region should implement strategic transformation to improve energy efficiency. The eastern region should reduce its dependence on foreign energy and improve its energy efficiency by adopting the following measures: first, the eastern region should encourage the transfer of applicable technologies and mature industries to Latin America, Eastern Europe and African countries, which can not only expand the market, but also reduce energy consumption and external energy dependence. Second, local governments should encourage the transfer of appropriate technologies and mature industries And funding the research and development and application of biofuel and oil gas mixing technology. 


\section{Conclusion}

Based on the empirical research and analysis found that with the improvement of level of economic growth, China's economic growth inhibitory effect on new energy mainly concentrated in the western region. Therefore, the western region should increase research and development funds and personnel investment. First, reform R \& D investment and broaden R \& D funding channels. At the same time, the government can establish an evaluation system for $\mathrm{R} \& \mathrm{D}$ investment to promote $\mathrm{R} \& \mathrm{D}$ investment. If the $\mathrm{R} \& \mathrm{D}$ expenditure of an enterprise meets or exceeds the prescribed standards, the tax authorities shall reduce the enterprise income tax, and vice versa.

\section{References}

1. Bilgili, F., Koçak, E., and Bulut, Ü. (2016). The dynamic impact of renewable energy consumption on CO2 emissions: a revisited environmental KUZNETS curve approach. Renewable \& Sustainable Energy Reviews, 54, 838-845.

2. Lee, J. W. (2013). The contribution of foreign direct investment to clean energy use, carbon emissions and economic growth. Energy Policy, 55(4), 483-489.

3. Mo Shenxing. On the principle of combining energy development and utilization with environmental protection against the background of climate change [J]. Political and legal issues, 2011 (5)

4. Qi Shaozhou, Li Yang. Does renewable energy consumption affect economic growth? -- An Empirical Study Based on the EU [J]. World economic research, 2017 (04): 106-119+ 136

5. Wei Jiaqi, research on the correlation between coal enterprise integration and enterprise performance [D]. 2018, Shanxi University of Finance and economics

6. Shi Jingli. Thoughts on the development mechanism of renewable energy in the post subsidy era [J]. Wind energy, 2019, (8) 